\title{
'Face-to-Face vs. Flipped': A Comparative Study on Academic Outcomes and Learning Preferences in First Year Allied Health Students Undertaking Anatomy and Physiology
}

\author{
Lauren Wendt, Eugene Du Toit, Helen Naug \\ School of Pharmacy and Medical Sciences, Griffith University, Australia.
}

\begin{abstract}
A mixed-mode or "flipped" model of learning focusses on supporting a high level of student engagement, student motivation, and the transferability of specific course content. A blend of online resources and face-to-face $(F 2 F)$ learning facilitates meaningful interaction between peers, while building a capacity for self-directed and lifelong learning. Within the School of Medical Science, Anatomy and Physiology (A\&P) content was 'flipped' for delivery at a new campus to align with the traditional F2F offering. Lectures were delivered online, while tutorials and practicums were F2F. Collaborative learning opportunities utilizing active learning pedagogies was appealing and was integrated during the re-alignment of $A \& P$ which was delivered to a cohort of allied health students undertaking their first year of their program. This study assessed how this type of learning was received by students (from the same program) undertaking the same course in an on-campus F2F delivery. Students completed surveys relating to their experiences in learning activities applied in: lectures, tutorials and practicums. In addition, academic outcomes (theoretical and practical) across the two modalities were also evaluated. Overall, students undertaking the mixed-mode delivery performed significantly better in theoretical assessments, while performance in practical assessments was comparable between both deliveries. Student preferences to learning and teaching activities was mixed, however all students highly valued the use of "mini-quizzes" in lectures, tutorials and practicums.
\end{abstract}

Keywords: Flipped; mixed-mode; allied health; undergraduate; anatomy and physiology. 


\section{Introduction}

The Anatomy curriculum has undergone dramatic transformations in the $21^{\text {st }}$ century to include modifications of in-person teaching, clinical placement, problem-based learning activities and gross anatomy teaching using cadaveric specimens (Leung et al., 2006; Parker, 2003; Shead, 2020). Learning anatomy dates back to the early Renaissance period, with the Greek root for 'anatomy' is to 'cut up' (McLachlan \& Patten, 2006). For centuries, clinicians undertook many hundreds of hours studying and reviewing the distinctive contours and forms of the human body via human dissections. Becoming a qualified health professional was paramount to having an advanced understanding of human form and function (Khalil et al., 2018; Granjeiro, 2019). The global emergence of the pedagogical 'flipped' classroom' model has challenged anatomy educators in transitioning away from the traditional didactic 'teacher' to a student-centered approach. Blended learning represents a mixed delivery of educational resources delivered via a combination of F2F delivery and online resources essentially a complete transformation of accessibility of information for students outside of the traditional classroom setting (Norberg et al., 2011). Many Universities saw the adoption of blended learning models as a means of offering educational platforms to a more diverse student population, while promoting a cost-effective option in the long-term (Garrison \& Kanuka, 2004). Blended learning provides students with learning experiences that are flexible, collaborative and independent - all of which are advantageous in creating meaningful learning experiences. Based on the active learning strategies that form the foundation of 'flipped' classroom instruction, the overall goal of a 'flipped' classroom was to improve student outcomes compared to the traditional F2F delivery. Several studies have supported this theory and showed positive gains in student performance in medical education (Street et al., 2015; Stockwell, 2015). While 'flipping' does not always improve student performance (He, 2019), it does suggest that not all disciplines are potential candidates for 'flipped' instruction. At Griffith University (within the School of Medical Science), first year A\&P courses have always followed traditional F2F delivery. While the courses were (and still are) popular with students, there was a distinct lack of flexibility and accessibility. The flexible model for Foundation Year Health (FYH) was introduced, and A\&P course content was redesigned into a mixed-mode "flipped" classroom approach (online lectures, F2F tutorials, tutorial workbook and online assessment). In 2018, the "flipped" delivery of A\&P was delivered to a cohort of allied health students at another campus, with the two courses (F2F and mixed-mode) running contemporaneously. Notwithstanding individual differences in teaching format and the student cohort, the main point of difference between the courses was the mode of lecture delivery. Therefore, the overall aim of this study was to assess student outcomes and preferences to teaching and learning activities across the two deliveries in a unique cohort of allied health students. 


\section{Methods}

\subsection{Participants}

Study participants were allied health science students enrolled in an undergraduate program of either a Bachelor or Physiotherapy or a Bachelor of Occupational Therapy. Students were enrolled in courses 1016MSC (Anatomy and Physiology Systems 1) and 1017MSC (Anatomy and Physiology Systems 2) in 2019 in the first year of their undergraduate study. Students were invited to participate in a survey (via email) that related to their learning preferences in the course.

\subsection{Course Model: Learning Activities and Assessment}

Course content was aligned across both campus offerings (NA campus - mixed delivery) and (GC campus - F2F) (Table 1). Students enrolled in the F2F offering attended $\sim 3 \mathrm{hr}$ lectures/weekly; $10 \mathrm{x}$ practicums ( $\sim 3 \mathrm{hrs}$ each); $1 \mathrm{hr}$ tutorial/ weekly (non-compulsory). Students enrolled in the mixed-mode offering participated in: $\sim 1.5 \mathrm{hr}$ online lectures/weekly; $10 \mathrm{x}$ practicums $(\sim 3 \mathrm{hr}$ each); and $\sim 2 \mathrm{hr}$ tutorial/weekly (compulsory). Assessment was undertaken in-person at both campuses including $2 \mathrm{x}$ theoretical examinations (MCQ $+\mathrm{SA}$ responses) and $2 \mathrm{x}$ practical examinations. The mean (\%) scores of all summative assessment items were examined across both modalities for all allied health students enrolled in Anatomy and Physiology Systems 1 and 2 (NA campus $\sim 119$ students; GC campus $\sim 96$ students).

Table 1. Learning Activities over 12-week Trimester.

\begin{tabular}{lll}
\hline Learning Activities & Face-to-face & Mixed-Mode \\
\hline Lectures & $\sim 3 \mathrm{hr} /$ weekly (in-person) & $1.5 \mathrm{hr} /$ weekly (online) \\
Tutorials & $\sim 1 \mathrm{hr} /$ weekly (non-compulsory) & $\sim 2 \mathrm{hr} /$ weekly \\
Practicums & $\sim 3 \mathrm{hrs}$ ( x 10) & $\sim 3 \mathrm{hrs}$ ( x 10) \\
Total Time (hr) & $\sim 77 \mathrm{hrs}$ & $\sim 72 \mathrm{hrs}$ \\
\hline
\end{tabular}

\section{Results}

Student preferences for teaching and learning activities were categorised across lectures, tutorials and practicums for each offering (Fig. 1 \& Fig. 2). Students ranked the 'effectiveness' of each of the learning activities used in the course on a scale from 1-5. (' 1 ' Extremely Effective - '5' Least effective). 83\% of students undertaking the mixed-mode delivery of A\&P indicated that the "use of analogies" in online lectures was extremely effective, while $64 \%$ indicated the use "mini-quiz's" as being an equally effective learning activity. Student preferences in F2F lectures were mixed (Fig. 2A), with 50\% of students indicating that the inclusion of "mini-quizzes" during lectures was 'extremely effective', 
followed closely by $33 \%$ reporting the "use of analogies", and $25 \%$ for "animations/audiovisuals".

\section{(A) LECTURES (online mini-lectures)}

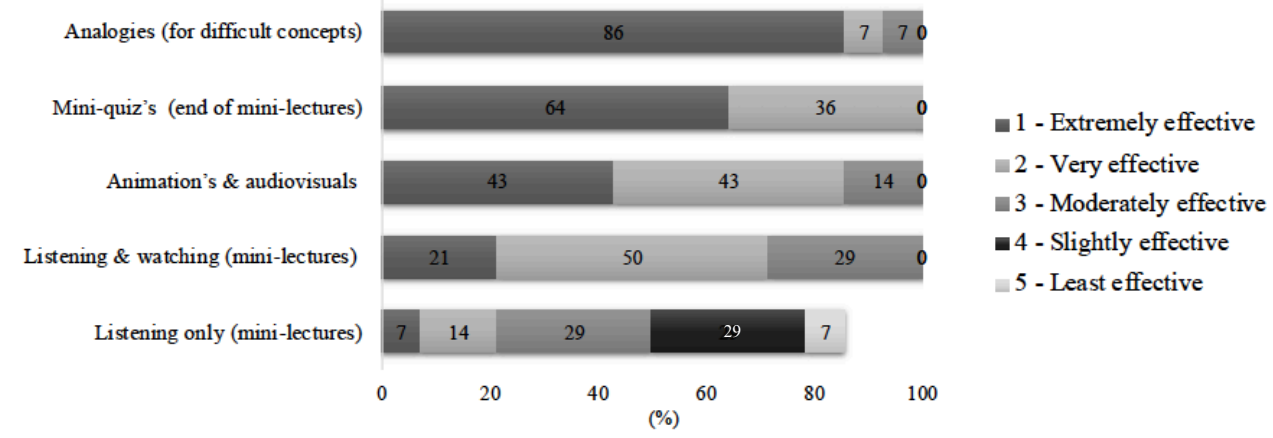

\section{(B) TUTORIALS (face-to-face)}

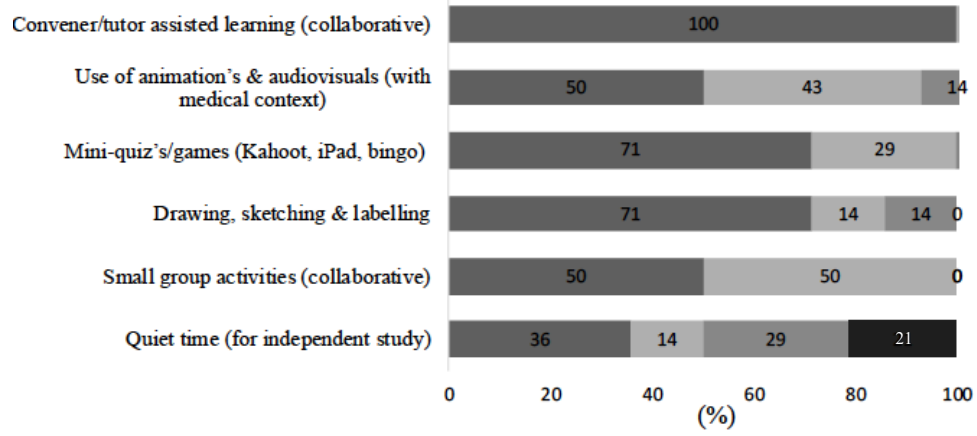

\section{(C) LABORATORIES/PRACTICUMS (face-to-face)}

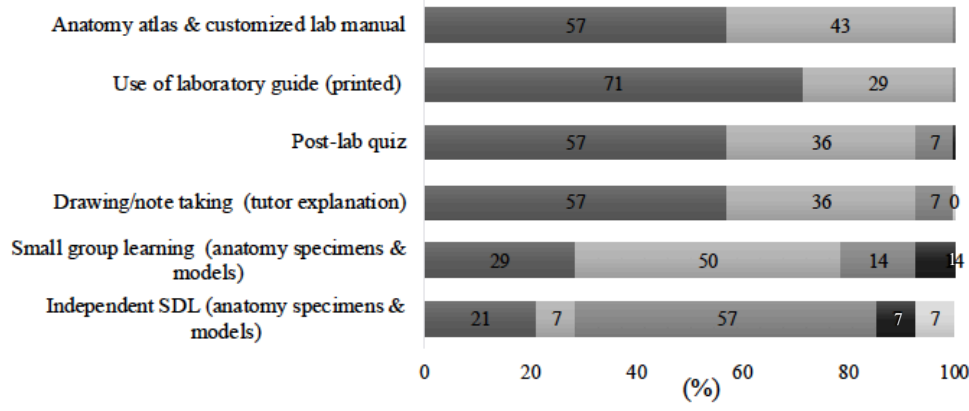

1 - Extremely effective $\square 2$ - Very effective 3 - Moderately effective 4 - Slightly effective 5 - Least effective

Figure 1. Student Learning Preferences in Anatomy \& Physiology (Mixed-Mode offering). Students' preferences to learning activities (on a 1-5 scale) used in online lectures (A); tutorials (B) and laboratories/practicums (C). 
(A) LECTURES (face-to-face)

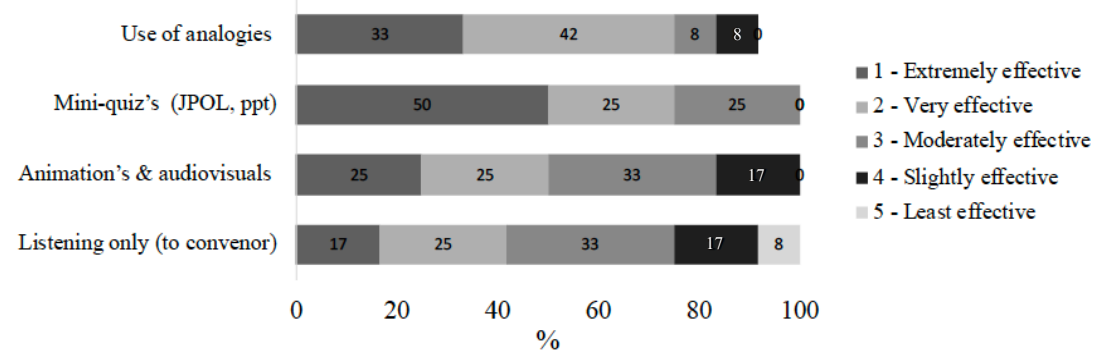

(B) TUTORIALS (face-to-face )

Convener/tutor assisted leaming (collaborative)

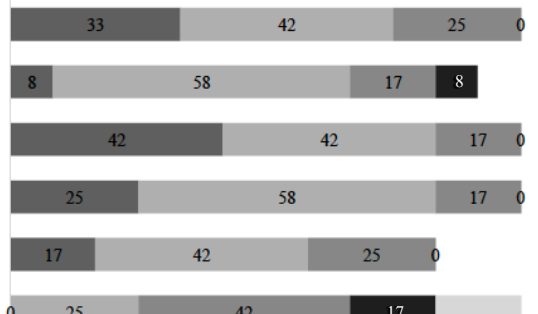

- 1 - Extremely effective

Animation's \& audiovisuals

Mini-quiz's (JPOL or Kahoot)

Drawing, sketching \& labelling activities

Collaboration (Small group activities)

Use of quiet time (independent study)

25

20

$40 \% 60$

80

100

$=2$ - Very effective

= 3 - Moderately effective

- 4 - Slightly effective

5 - Least effective

(C) LABORATORIES/ PRACTICUMS (face-to-face)

Anatomy atlas \& customized lab manual

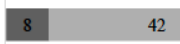

42

33

17
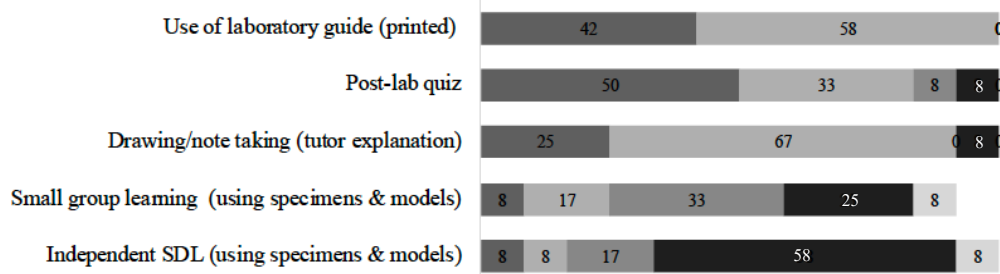

- 1 - Extremely effective

$=2$ - Very effective

=3 - Moderately effective

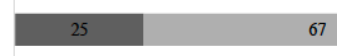

67

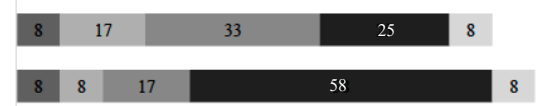

- 4 - Slightly effective

$=5$ - Least effective

$\begin{array}{lllllll}0 & 20 & 40 & \% & 60 & 80 & 100\end{array}$

Figure 2. Student Learning Preferences in Anatomy \& Physiology (F2F). Students' preferences to learning activities (on a 1-5 scale) in F2F lectures (A); tutorials $(B)$ and laboratories/practicums $(C)$

Other variables evaluated were: self-reported attendance, usage of course and non-course resources and study group attendance (Fig. 3). Attendance (Fig. 3A) was high in the survey respondents, with most students indicating they attended $75-100 \%$ of all classes. Attendance at peer assisted study sessions (P.A.S.S) was higher (Fig. 3B) amongst students who attended the F2F offering ( $40 \%$; 'very frequent') vs. mixed-mode ( $20 \%$; 'very frequent'). Students undertaking the mixed-mode offering reported a greater use of non-course resources $(\sim 33 \%$; 'frequent' \& 20\%; 'occasional') (Fig. 3C). Comparatively, in the F2F offering, only 9\% of students reported 'frequent'. Non-course resources listed by students across both modalities included: Crash course, Khan academy, YouTube, visible body, Ninja Nerd, Flash cards and Amoeba Sisters. 
(A) Attendance (all classes)

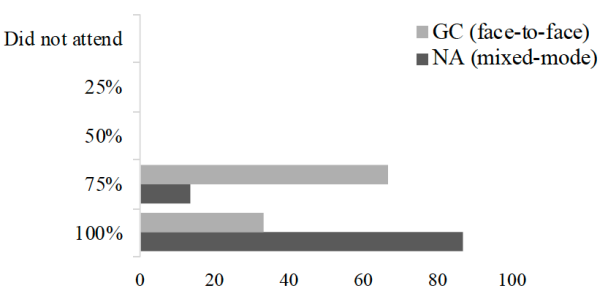

(B) P.A.S.S (attendance)

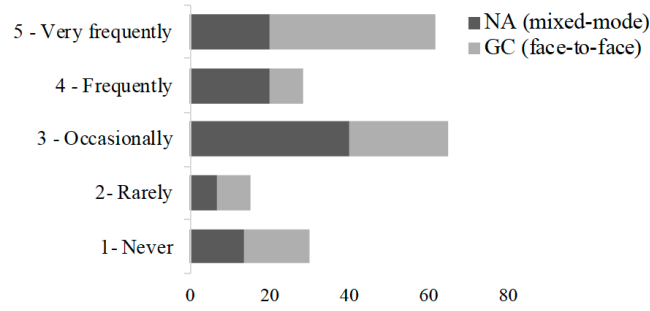

(C) Study Group (attendance)

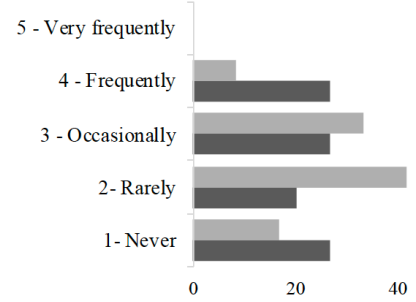

(D) Use of Non-Course Resources

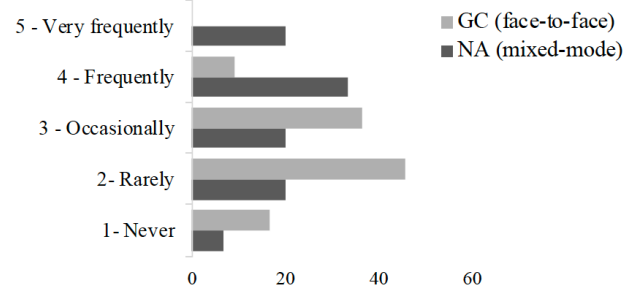

(E) Feeling Overwhelmed (frequency)

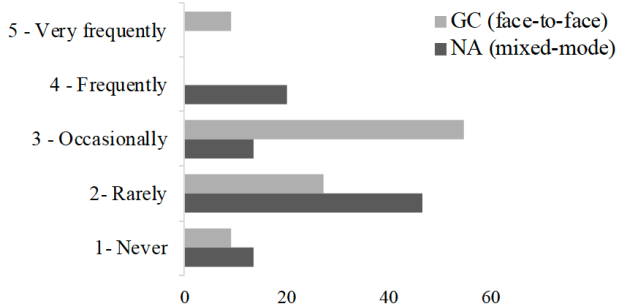

(F) Course Learning Objectives (confidence)

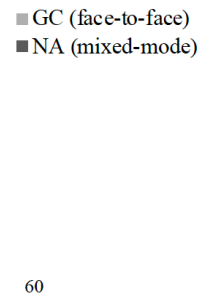

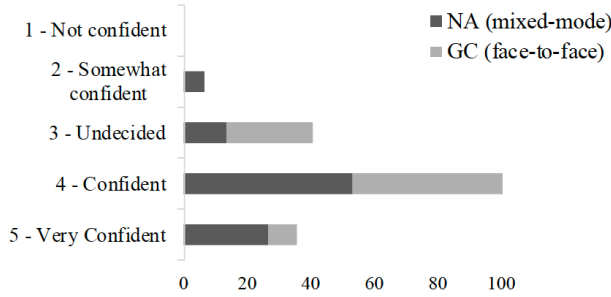

Figure 3. Student attendance (A); P.A.S.S attendance; study group attendance (C); use of non-course resources $(D)$; feeling overwhelmed by course resources $(E)$; \& confidence in course learning objectives $(F)$.

The mean mark for theoretical assessments for both A\&P courses (1016MSC/1017MSC) was significantly higher for students undertaking the mixed-mode delivery (Table $2 \&$ Table 3 ) compared to students undertaking the F2F delivery (mid-trimester \& end-of trimester exam). 
Table 2. Assessment Outcomes for Anatomy and Physiology Systems 1.

\begin{tabular}{lccccc}
\hline Assessment Items & \multicolumn{4}{l}{ GC (face-to-face) } & \multicolumn{4}{l}{ NA (mixed-mode) } & \\
\hline & M (\%) & SD & M (\%) & SD & P \\
Laboratory/Practical Exam 1 & $79.9 \%$ & 14.8 & $79.1 \%$ & 16.8 & 0.7170 \\
Mid-Trimester Exam 1 & $67.6 \%$ & 15.1 & $74 \%$ & $12.7^{*}$ & 0.0010 \\
Laboratory/Practical Exam 2 & $76 \%$ & 15.9 & $75.8 \%$ & 15.6 & 0.9034 \\
End of Trimester Exam & $65.4 \%$ & 17.6 & $72.1 \%$ & $15.7^{*}$ & 0.0038 \\
Overall course weight (\%) & $71.1 \%$ & 14.4 & $75.2 \%$ & $14.0^{*}$ & 0.0377 \\
students with grades $(n)$ & 94 & & 118 & & \\
\hline
\end{tabular}

Note. Mean (\%) (+SD) *, $P<0.05$

Table 3. Assessment Outcomes for Anatomy and Physiology Systems 2.

\begin{tabular}{lccccc}
\hline Assessment Items & \multicolumn{4}{l}{ GC (face-to-face) } & \multicolumn{2}{l}{ NA (mixed-mode) } & \\
\hline & M (\%) & SD & M (\%) & SD & P \\
Exam 1 & $67.3 \%$ & 14.6 & $75.5 \%$ & $13.0^{*}$ & 0.0001 \\
Laboratory/Practical Exam 1 & $66.2 \%$ & 14.2 & $68 \%$ & 13.3 & 0.3719 \\
Exam 2 & $61.9 \%$ & 17.6 & $73.7 \%$ & $13.7^{*}$ & 0.0001 \\
Laboratory/Practical Exam 2 & $74.3 \%$ & 15.9 & $79.7 \%$ & 12.6 & 0.0098 \\
End of Trimester Exam & $58.8 \%$ & 17.5 & $64.5 \%$ & $14.1^{*}$ & 0.0139 \\
Overall course weight (\%) & $63.6 \%$ & 16.1 & $71.5 \%$ & $11.5^{*}$ & 0.0001 \\
students with grades $(n)$ & 80 & \multicolumn{5}{c}{110} \\
\hline
\end{tabular}

Note. Mean $(\%)(+S D) *, P<0.05$

\section{Discussion}

The mean result for theoretical assessments for students undertaking the mixed-mode delivery (for 1016MSC) was significantly higher compared to students undertaking the F2F delivery (mid-trimester and end-of trimester exam), while the mean result for the practical examinations was comparable between both modalities (F2F vs. mixed-mode). For course 1017 MSC (Trimester 2), the mean result for all assessment items was significantly higher for students in the mixed-mode delivery vs. the F2F offering. These outcomes suggest that a mixed-model 'flipped' of learning does improve students' performance in summative assessments, and that this modality may well be suited to A\&P courses. Improvements in student performance may be attributed to the availability of self-directed study material and effective use of in-class discussion that accompanies collaborative and student directed learning. Teaching and learning strategies that aim to expand student's application of knowledge and develop higher order thinking skills, preparing them more adequately for high-level cognitive questions which are used in theoretical assessments (Anderson, 2001; Day, 2018). Didactic lectures are limited to providing students with learning opportunities 
to apply knowledge in a collaborative setting, thus may contribute a negative impact on their performance in theoretical assessments (Lochner, et al., 2016). Student preferences to teaching and learning activities were mixed amongst students attending F2F lectures. 50\% of students indicating that the inclusion of "mini-quizzes" during lectures was "extremely effective', closely followed by the inclusion of "analogies" $(\sim 33 \%)$ and "animations/audiovisuals" ( $25 \%)$. Although didactic lectures are widely criticized (McLaughlin, 2001) advances in technology have enabled tertiary educators to reinvigorate their practice and presentation style to enhance the student learning experience (Gurpinar, 2011). Tutorial attendance is compulsory in the 'mixed-mode' offering of A\&P, thus students are frequently immersed in active learning environments which provide opportunities to apply knowledge using concepts introduced in online lectures. Student preferences to teaching and learning activities used in tutorials was mixed, with most activities ranked as "very effective". Students highly valued: "collaborative" learning (with tutors/convenor), "miniquiz's", "drawing and labelling" activities and working in "small groups". Contrary to the mixed-mode offering, tutorials in the F2F offering are not compulsory and are shorter in duration $(\sim 1 \mathrm{hr})$. Students indicated that most teaching and learning activities used were "extremely effective" or "very effective". The use of "mini-quizzes" was highly regarded, with $42 \%$ of survey respondents denoting them as a "extremely-effective" activity. Students across both modalities of A\&P valued the use of formative quizzes in lectures, tutorials and practicums as an effective learning tool. Students who regularly undertake quizzes as formative assessment achieve better outcomes in summative assessment items (Kromann, 2009; Kibble, 2007; Roediger et al, 2011). Practice questions are advantageous in that students can use them as performance indicators to measure their learning. Attendance at peer assisted study sessions (P.A.S.S) was higher amongst F2F students $(\sim 40 \%)$ vs. mixed-mode $(\sim 20 \%)$. A lower attendance may be attributed to mixed-mode students attending tutorials that are longer in duration ( $2 \mathrm{hr} / \mathrm{wk}$.), compared to GC students ( $\sim 1 \mathrm{hr} /$ wk.). In addition, F2F students attend all classes in-person, making P.A.S.S sessions more accessible. Students undertaking the mixed-mode offering reported a greater use of non-course resources. The most commonly utilized non-course resources listed by students across both deliveries were: Crash course, Khan academy, YouTube, visible body, Ninja Nerd, Flash cards and Amoeba Sisters. Jaffar (2012) suggests that more frequent use of non-course resources is expected amongst students undertaking blended courses, as lecture material is online and additional digitalized content is more accessibile.

\section{Conclusions}

Students undertaking the mixed-mode delivery performed significantly better in theoretical assessments compared to students in the F2F delivery.. Student preferences to teaching and learning activities was mixed across lectures, tutorials and practicums. A trend emerged that 
students (across both modalities) highly valued the inclusion of 'mini-quizzes'. This evaluation of student preferences to teaching and learning activities can assist in tailoring A\&P course design to support student learning.

\section{References}

Anderson, L.W., Krathwohl D.R., Airasian P.W., Cruikshank K.A., Mayer R.E., Pintrich P.R., Raths J., \& Wittrock M.C. (2001). A Taxonomy for Learning, Teaching, and Assessing: A Revision of Bloom's Taxonomy of Educational Objectives. 1st Ed. New York, NY: Longman. 336 p.

Day, L.J. (2018). A gross anatomy 'flipped' classroom effects performance, retention, and higher-level thinking in lower performing students. American Association of Anatomists, $11,565-574$.

Garrison, D.R., \& Kanuka, H. (2004). Blended learning: Uncovering its transformative potential in higher education. Internet and Higher Education, 7(2), 95-105.

Granjeiro, E.M. (2019). Research-based teaching-learning method: a strategy to motivate and engage students in human physiology classes. Advances in Physiology Education. 43:4, 553-555

Gurpinar, E., Bati H., \& Tetik C. (2011). Learning styles of medical students change in relation to time. Advanced Physiology Education, 35, 307-11.

He, W., Holton, A., Gu, H., Warschauer, M. \& Farkas, G. (2019). Differentiated impact of flipped instruction: when would flipped instruction work or falter? International Journal of Teaching and Learning in Higher Education, 31(1), 32-49.

Jaffar, A.A. (2012). YouTube: An emerging tool in anatomy education. Anatomical Science Education, 5, 158-164.

Khalil, M.K., Abdel Meguid, E.M. \& Elkhider, I.A. (2018), Teaching of anatomical sciences: A blended learning approach. Clinical Anatomy, 3, 323-239

doi: org/10.1002/ca.23052

Kibble, J. (2007). Use of unsupervised online quizzes as formative assessment in a medical physiology course: Effects of incentives on student participation and performance. Advances in Physiology Education, 31, 253-260.

Kromann, C.B., Jensen M.L., \& Ringsted C. (2009). The effect of testing on skills learning. Medical Education, 43, 21-27.

Lochner, L., Wieser, H., Waldboth, S., \& Mischo-Kelling, M. (2016). Combining traditional anatomy lectures with e-learning activities: How do students perceive their learning experience? International Journal of Medical Education, 7,69-74. doi:/dx.doi.org.libraryproxy.griffith.edu.au/10.5116/ijme.56b5.0369

Leung, K., Lu, K., Huang, T., \& Hsieh, B. (2006). Anatomy instruction in medical schools: connecting the past and the future. Adv Health Sci Educ Theory Pract, 11, 209-215. doi: org/10.1007/s10459-005-1256-1 
McLaughlin, K., \& Mandin H.A. (2001). Schematic approach to diagnosing and resolving lecturalgia. Medical Education, 35, 1135-1142. doi: 10.1046/j.13652923.2001.01090.x.

McLachlan, J.C. \& Patten, D. (2006), Anatomy teaching: ghosts of the past, present and future. Medical Education, 40: 243-253

Norberg, A., Dziuban. C.D., Moskal, P.D. (2011). A time-based blended learning model. On the Horizon, 19 (3) 207-216. doi: 10.1108/10748121111163913

Parker, L.M. (2002). Anatomical dissection: Why are we cutting it out? Dissection in undergraduate teaching. ANZ Journal of Surgery, 72, 910-912.

Roediger, H.L., Agarwal P.K., McDaniel M.A., \& McDermott K.B. (2011). Test-enhanced learning in the classroom: Long-term improvements from quizzing. Journal of Experimental Psychology: Applied, 17, 382-395.

Shead, D.A., Roos R., Olivier B., \& Ihunwo A.O. (2020). Curricular and pedagogical aspects of gross anatomy education for undergraduate physiotherapy students: a scoping review. JBI Evidence Synthesis, 8: 893-951

Stockwell, B.R., Stockwell M.S., Cennamo M., \& Jiang E. (2015). Blending learning improves science education. Cell, 162: 933-936.

Street, S.E., Gilliland, K.O., McNeil, C. \& Royal, K. (2015). The flipped classroom improved medical student performance and satisfaction in a pre-clinical physiology course. Med.Sci.Educ. 25, 35-43. 